\title{
Olhares de Crianças sobre a Família: Um Enfoque Quantitativo ${ }^{1}$
}

\author{
Ana Maria Almeida Carvalho \\ Lúcia Vaz de Campos Moreira \\ Elaine Pedreira Rabinovich \\ Universidade Católica de Salvador
}

\begin{abstract}
RESUMO - Este estudo investigou concepções de crianças sobre a família. Participaram 120 crianças dos dois sexos, entre 5 e 12 anos, do Nordeste e Sudeste do País, em dois contextos urbanos (capital e interior) e níveis socioeducacionais médio alto e baixo. Utilizou-se roteiro semi-estruturado de entrevista individual. Os resultados mostraram que as concepções das crianças sobre quem faz parte da família não refletem coabitação, mas, possivelmente, a convivência com outros parentes (avós, tios, primos); geração foi um diferencial mais importante do que gênero na definição dos perfis de pai, mãe, irmãos, avô e avó; família apareceu como necessidade básica, lugar de pertencimento e de identidade, mas as crianças têm dificuldade para definir o conceito. São discutidas questões metodológicas e apontadas direções para pesquisas futuras.
\end{abstract}

Palavras-chave: concepções sobre família; concepções de crianças; entrevista com crianças.

\section{Children's Conceptions of Family: A Quantitative Approach}

\begin{abstract}
The study investigated children's conceptions of family. Participants were 120 boys and girls aged 5-12, from two Brazilian regions (Northeast and Southeast), two urban contexts (capitals and inland cities), and from upper middle and lower socioeconomic strata. Children were interviewed individually according to a semi-structured interview syllabus. The results showed that children's conceptions of who belongs to the family do not reflect cohabitation, but, possibly, the degree of companionship with other relatives (grandparents, uncles and aunts, cousins); generation was a stronger differential than gender for the definition of father's, mother's, siblings', grandfathers' and grandmothers' profiles; family was pictured as a basic need, locus of identity and belongness, but children find it difficult to define the concept. Methodological questions are discussed and directions for future research are pointed out.
\end{abstract}

Keywords: conceptions on family; children's conceptions; interviews with children.

Já é consensual no discurso da Psicologia do Desenvolvimento a concepção da criança como agente ativo de seu próprio desenvolvimento, dotada de um repertório social complexo e sofisticado desde o nascimento. Como parte desse repertório, devem ser consideradas as percepções e concepções que virão a orientar a criança em suas interações e relações com outros - nesse caso, com a família. Pode-se supor que as concepções e percepções da criança a respeito da família, bem como sobre outros aspectos do mundo em que vive, são constituídas em sua interação ativa e seletiva com seu ambiente familiar imediato - um microssistema -, com outros ambientes sociais tais como a escola - cujas relações com a família e com outros microssistema compõem mesossistemas - e, ainda, com os valores e concepções prevalentes no contexto social mais amplo (exossistema) e no macrossistema, contexto sociohistórico do qual o exossistema faz parte (Bronfenbrenner, 1979/1996; Goetz \& Vieira, 2008).

1 As autoras agradecem à Dra. Katharina E. A. Beraldo (UNIFIEO, SP), à Dra. Célia Nunes Silva (UFBa), à pedagoga Lia Vaz de Campos, à psicóloga Andréa Magalhães, às alunas Daisy Alves, Ivone da Silva, Leonor Guimarães, Rita de Cássia de Moraes e Roberta Chaves, do Programa de Pós-Graduação em Família na Sociedade Contemporânea (UCSal), e à bolsista de iniciação científica Stella Pinheiro (FAPESB), pela colaboração na coleta de dados.

2 Endereço para correspondência: Rua da Invernada, 12, Fazendinha. Carapicuíba, SP. CEP 06355-340. Fone: (11) 416987 32. E-mail: amacarva@uol.com.br.
Em que consistem essas percepções e concepções, qualquer ou quaisquer que sejam as suas origens? Já as conhecemos suficientemente? Hinde (1982) sustenta que uma ciência das relações requer uma base descritiva. Nesse contexto situam-se a análise e a discussão propostas no presente artigo: a compreensão da inserção da criança na família e dos papéis desta em seu cotidiano requer - entre muitas outras coisas - a investigação das concepções da própria criança a esse respeito, partindo de uma caracterização descritiva. Como apontam Goetz e Vieira (2008), a definição de família deve ser baseada (também) na opinião de seus membros.

Apesar do consenso atual sobre criança como agente, ainda são poucos os estudos que se dirigem à própria criança como fonte de dados descritivos a respeito da família, bem como os que utilizam a entrevista com crianças como procedimento de coleta de dados (Carvalho, Beraldo, Pedrosa \& Coelho, 2004). O foco principal em estudos sobre a família continua sendo nas mães (e.g., Braga \& Amazonas, 2006; Dessen \& Braz, 2000; Moreira, 2005) ou, mais recentemente, nos pais (e.g., Gomes \& Resende, 2004). Dentre os poucos estudos que focalizam os filhos, encontram-se o de Souza (2000), que entrevistou adolescentes de 14 a 18 anos sobre suas percepções acerca da separação dos pais, e o de Goetz e Vieira (2008), com crianças de 11 e 12 anos, que não utilizou entrevista, e sim um instrumento padronizado. Esse estudo, embora com objetivos, faixa etária focalizada e instrumento diferente, é o que mais se aproxima do presente trabalho 
em termos de enfoque e metodologia, empregando análise quantitativa e um referencial teórico semelhante.

Partindo desse cenário, o estudo aqui relatado visa complementar e integrar análises qualitativas anteriores, realizadas sobre o mesmo conjunto de dados de entrevistas com crianças residentes em Salvador (Moreira, Rabinovich \& Silva, 2009) e em São Paulo (Rabinovich \& Moreira, 2008) a respeito de suas concepções sobre família. Na presente análise o conjunto total de dados foi analisado quantitativamente, priorizando-se a discussão dos seguintes aspectos metodológicos: o procedimento de entrevistas com crianças, a questão da categorização com vistas a uma análise quantitativa e uma comparação entre os potenciais desta e da análise qualitativa com o tipo de dado coletado.

A opção por entrevistas como procedimento de coleta traz implícito o pressuposto de que as verbalizações da criança estarão expressando suas percepções e concepções sobre a família e que, como tal, poderão ser analisadas e interpretadas. Deve ficar claro que elas não constituem necessariamente um retrato factual sobre as relações e os papéis efetivamente vividos no ambiente familiar de cada criança (Carvalho \& cols., 2004). O que a criança oferece em suas verbalizações é sua compreensão a respeito de suas experiências e do que lhe chega mediado por seus parceiros sociais, e é essa compreensão que pode ser analisada.

Embora não esteja no âmbito deste trabalho a questão sobre a origem das compreensões da criança sobre suas experiências na família, ou seja, se elas se originam no micro, meso, exo ou macrossistemas ou em mais de um deles, a amostragem utilizada criou a possibilidade de que algumas pistas a respeito dessa questão pudessem ser identificadas: ao diversificar a amostra em termos de regiões do país (Nordeste e Sudeste), de contextos urbanos (capitais e cidades do interior) e de nível socioeducacional (médio alto e baixo), poder-se-ia esperar que eventuais diferenças apontassem para a presença de fatores exossistêmicos e/ou macrossistêmicos na compreensão das crianças a respeito de família.

Objetiva-se neste estudo, portanto, explorar as possibilidades de uma análise quantitativa com base em entrevistas semi-estruturadas realizadas com crianças de 5 a 12 anos, de regiões diferentes do país e de níveis socioeconômicos diversos, sobre suas concepções de família, e refletir sobre questões metodológicas envolvidas nessa proposta.

\section{Método}

\section{Participantes}

Foram entrevistadas 120 crianças brasileiras entre 5 e 12 anos de idade, sendo metade da Região Sudeste e a outra metade da Região Nordeste e, dentre estas, 30 nas capitais e 30 em cidades do interior. Cada um desses segmentos foi dividido em dois grupos: um com 15 crianças cujos pais apresentavam nível socioeducacional (NSE) baixo e outro com 15 crianças de NSE médio alto. Gênero e idade das crianças não foram controlados na amostra, garantindo-se apenas a inclusão de crianças de ambos os gêneros e dentro da faixa etária delimitada.

\section{Instrumentos}

Como instrumentos de coleta da pesquisa foram utilizados:

(a) um roteiro sobre as concepções de família e de seus membros, aplicado às crianças em entrevistas individuais semi-estruturadas, contendo perguntas como: O que é família para você? Como é a sua família? O que é ser pai? O que é ser mãe? Você tem irmãos?; Para que serve um irmão? Como é ser irmão? Você tem avós?; Como é ser vovó? Como é ser vovô?. O modo de formular as perguntas podia variar com vistas a explorar mais ou encorajar as respostas das crianças (por exemplo, o que faz o pai/ como é o pai etc.).

(b) um questionário sociodemográfico sobre a composição da família, local da moradia, conjunto de moradores, suas idades, sexo, escolaridade e profissão dos pais, que foi respondido por escrito pelos pais ou responsáveis e entregue posteriormente aos pesquisadores.

\section{Procedimento}

As entrevistas foram realizadas com a anuência dos responsáveis, que assinaram o Termo de Consentimento Informado. O trabalho foi submetido e aprovado pelo Comitê de Ética em Pesquisa da Universidade Católica do Salvador (UCSal). As entrevistas, gravadas em áudio e posteriormente transcritas, foram realizadas por pesquisadores e por alunos do programa de pós-graduação em Família na Sociedade Contemporânea (UCSal), em locais combinados com os participantes (casa, escola ou outros) e com duração variável (10 a 30 minutos, dependendo da idade e de outras características da criança).

\section{Análise de dados}

Todas as comparações estatísticas foram feitas pela Tábua de Limites Exatos de Confiança para Porcentagens (Ciba-Geigy, 1971), ao nível de significância de 95\%.

\section{Resultados e Discussão}

\section{A concepção de família baseia-se em coabitação ou inclui outros critérios?}

As informações dos pais sobre moradores na residência, associadas às respostas das crianças sobre os itens do roteiro de entrevista referentes a concepções sobre a família, permitiram explorar essa questão. Para tanto, essas informações foram cruzadas, utilizando as seguintes categorias: Nuclear $(\mathrm{N})$, onde moram apenas pais e filhos (moradia) ou onde ape- 
Tabela 1. Tipo de moradia (quem mora junto) x composição da família (quem faz parte).

\begin{tabular}{lcccc}
\hline \multirow{2}{*}{ Composição } & \multicolumn{4}{c}{ Moradia } \\
\cline { 2 - 5 } & Nuclear & Ampliada & Extensa & Total (\%) \\
\hline Nuclear & 30 & 1 & 51 & $82(77,3)$ \\
Ampliada & 1 & 7 & 7 & $15(14,1)$ \\
Extensa & 2 & 0 & 7 & $9(8,5)$ \\
Total (\%) & $33(32,0)$ & $8(7,5)$ & $65(61,3)$ & $106(100,0) *$ \\
\hline $\begin{array}{l}\text { Nota: * Nas 14 entrevistas restantes (13 do sudeste, capital, nível médio alto; uma do } \\
\text { sudeste, capital, nível baixo), uma ou ambas as questões não foram respondidas. }\end{array}$
\end{tabular}

nas estes são descritos como parte da família (composição); Ampliada (A), onde a moradia/composição acolhe mais um ou dois membros (avós ou, às vezes, tio/a); e Extensa (E), incluindo avós, tios, primos (moradia e composição).

A Tabela 1 apresenta os resultados desse cruzamento. Foram excluídos os casos em que uma ou ambas as questões não foram respondidas, resultando em uma amostra de 106 entrevistados. Observa-se que não existe relação entre as duas respostas: a maioria das moradias (77\%) é nuclear, enquanto a maioria das famílias descritas é extensa (65\%). A incidência de respostas NN (nuclear para moradia e para composição) é significativamente menor, e a de respostas NE (nuclear para moradia e extensa para composição) significativamente ${ }^{3}$ maior do que o esperado. Isso indica que a concepção da criança a respeito de quem faz parte da família não reflete o fato da coabitação, e sim, possivelmente, a convivência com outros parentes (avós, tios, primos); além disso, parece indicar que a criança discrimina, entre parceiros sociais com quem convive, aqueles que são parentes e os que são apenas amigos ou conhecidos. Essa discriminação poderia ser em parte resultado de nomenclatura diferenciada para parentes e não parentes; na atualidade, com o costume de atribuir o título de tia ou tio a não parentes, essa discriminação pode estar sendo mais difícil para a criança e depender de outros indícios.

Poder-se-ia supor que o domínio sobre a rede de parentesco se tornasse mais complexo com a idade, incorporando, por exemplo, a compreensão de tios como irmãos do pai ou da mãe, e/ou como esposas/maridos desses irmãos, e de avós como pais dos próprios pais, e ainda de alguns dos tios. Nessa hipótese, a compreensão da composição da família como extensa deveria aumentar com a idade. A idade dos respondentes não foi controlada na amostra deste estudo em termos de subgrupos de idade dentro da faixa de 5 a 12 anos; no entanto, quando divididos em dois subgrupos - dos 5 aos 8 anos e dos 9 aos 12 - resultaram acidentalmente 60 crianças por subgrupo, permitindo alguma exploração dessa possibilidade. A comparação, em termos desses subgrupos de idade, entre as crianças para as quais as duas informações

3 Sempre que utilizados aqui, os termos significância, significativo/a ou significativamente se referem a resultados estatisticamente significativos em relação ao esperado pelo acaso (hipótese nula), segundo os critérios do teste em questão. estavam relacionadas, isto é, por exemplo, moram com família nuclear e descreveram como nuclear a composição de sua família, não fortalece a suposição de uma maior compreensão da composição da família como extensa em função do aumento de idade: entre as 30 crianças cujos pais informaram moradia nuclear e que descreveram a família como nuclear, só nove eram do subgrupo mais jovem (significativo a 95\%).

Essa relação pode ser mais explorada. Esses 30 casos representam $36,5 \%$ dos 82 casos de moradia nuclear, contra $52(63,4 \%)$ em que a relação não ocorre. Os 30 casos são devidos principalmente a crianças do interior: 24 , contra seis nas capitais (significativo a $95 \%$ ). O que poderia significar essa maior incidência de NN no interior? Descreveria uma situação factual, ou seja, de inexistência de família extensa ou pouco contato com esta, ou algum tipo de relação diferenciada entre a criança e a família nuclear versus a extensa, ou ainda outros fatores? Questões a respeito da existência de família extensa e da convivência com ela (por exemplo, cotidiana, apenas em fins de semana e feriados, somente no Natal, ou nunca) não foram apresentadas sistematicamente às crianças entrevistadas; isso revela limitações no roteiro de entrevista e, principalmente, em seu aproveitamento como roteiro de entrevista semi-estruturada, que oferecia possibilidade de investigação de forma a aprofundar e/ou esclarecer as respostas das crianças.

De forma a investigar possíveis relações entre as respostas a questões sobre tipo de moradia e tipo de família e as variáveis principais do estudo (região, contexto urbano e nível socioeducacional), as combinações entre categorias de moradia e categorias de composição familiar (N, A e E) foram agrupadas em dois casos - a mesma categoria para as duas respostas e respostas diferentes para moradia e composição - e tabuladas separadamente para cada variável. Os percentuais sobre o total de respostas (106) e sobre o total de cada subgrupo por NSE não alcançam significância entre regiões e NSE; NN foi significativamente mais frequente no interior.

Estes dados indicam que a concepção de família não se baseia prioritariamente em coabitação, refletindo, também, ou principalmente, outros critérios a serem melhor investigados; que a noção de família extensa não está relacionada a aumento de idade; e que não há efeitos de região e de NSE, mas apenas um efeito de contexto urbano. 
Tabela 2. Número de respostas válidas, valorativas, não respondeu e não tem, para cada membro da família.

\begin{tabular}{lccccc}
\hline \multirow{2}{*}{ Tipo de resposta } & \multicolumn{5}{c}{ Membro da família } \\
\cline { 2 - 6 } & Pai & Mãe & Irmãos & Avô & Avó \\
\hline Válida & 174 & 196 & 231 & $110^{* *}$ & 150 \\
Valorativa & 8 & 3 & 0 & 8 & 14 \\
Não respondeu & 11 & 11 & 3 & 35 & 17 \\
Não tem & - & - & 4 & 12 & 2 \\
\hline
\end{tabular}

Nota: *significativamente alto; ** significativamente baixo; Int: interior; Cap: capital.

\section{Perfil dos membros da família}

A caracterização dos membros da família foi analisada a partir das respostas a perguntas sobre pai, mãe, irmãos, avô e avó (o que é ser... /como é o(a)... /o que faz o(a)...).

Ao caracterizarem os membros da família, as crianças utilizaram quase sempre atributos funcionais, ou seja, descritivos de funções ou atribuições de cada membro. Uma parte das respostas limitou-se a avaliações afetivas ou valorativas, como "é bom", "é bravo", "gosto muito" etc ("respostas valorativas"). Tais respostas poderiam ter sido aprofundadas com mais questões, como "por que", "como é ser bom/bravo" etc.; na ausência desse aprofundamento, as respostas ficaram muito genéricas e com pouco conteúdo passível de categorização; por esse motivo, decidiu-se utilizar apenas categorias funcionais nas análises principais ("respostas válidas").

A Tabela 2 apresenta os totais de respostas (válidas, valorativas, não respondeu e não tem), por membro da família. Esses últimos casos, em que um determinado membro (irmãos, avô ou avó) não existe na família, foram incluídos na análise desde que houvesse respostas válidas nessa condição.

É interessante notar as diferenças entre respostas válidas e não válidas (ou seja, valorativas, não respondeu e não tem) para cada membro da família: o maior número de respostas válidas ocorre para irmãos, seguidos por mãe, pai, avó e avô; respostas não válidas ocorreram mais para pai e avô, seguidos por avós, mãe e irmãos. Esses números, embora não alcancem significância exceto no caso do avô (respostas válidas significativamente baixas), são sugestivos de que alguns membros da família (mais especificamente, irmãos e mãe) são mais claramente conceituados em termos de funções e, portanto, mais facilmente descritos do que outros. Isso poderia decorrer de convivência mais intensa no cotidiano com as atividades das mães e, complementarmente, do fato de que a criança tem poucas oportunidades de observar o pai (ou o avô) no desempenho de tarefas no lar - o que sugere que esse desempenho é pouco frequente. Na comparação de respostas válidas em função das variáveis principais do estudo, não há diferenças significativas entre as regiões e quanto ao NSE; respostas válidas em relação à avó foram significativamente menos frequentes nas capitais e mais frequentes no interior, sugerindo maior proximidade com tal figura neste contexto urbano.

Para a caracterização do perfil dos membros da família, todas as respostas válidas foram inicialmente resumidas e tabuladas criança por criança, preservando-se sua distribuição de acordo com os valores das três variáveis. O exame dos conteúdos dessa tabulação conduziu à elaboração de categorias mais sintéticas e de significado aparentado. Assim, por exemplo, educar, ensinar, orientar, dar exemplo e aconselhar foram agrupadas em uma única categoria; mas sustentar e dar coisas foram mantidas separadas, porque a indicação contextual era diferente: sustentar incluiu respostas que utilizavam essa palavra, mas também outras que indicavam o provimento de necessidades, ao passo que o contexto de dar coisas sugeria um presentear eventual. Da mesma forma, foram tabuladas em separado as categorias cuidar, cuidar da casa e alimentar, uma vez que os contextos sugeriam diferenças de gênero e de geração na atribuição desses papéis.

A Tabela 3 e a Figura 1 (i, ii, iii) apresentam os perfis dos membros da família, agrupados em pares por geração - exceto no caso dos irmãos, onde não há informação sobre gênero. As porcentagens foram calculadas sobre o total de respostas válidas referentes a cada membro da família (soma de todas as categorias), podendo haver mais de uma resposta por entrevista; os valores descrevem, portanto, como cada membro da família se caracteriza em termos de funções desempenhadas ou quais funções mais caracterizam cada perfil. Na tabela são também indicadas as diferenças estatísticamente significativas encontradas em cada categoria e para cada membro da família.

Observa-se, inicialmente, que os perfis gerais de pai e mãe mostram-se mais semelhantes do que os de outros membros da família. Com exceção de "cuidar da casa" (categoria b), onde os perfis da mãe e do pai se afastam, em todas as outras categorias os dois perfis apresentam o mesmo desenho, com pequenas inversões de valor. $\mathrm{O}$ mesmo ocorre entre os perfis de avô e avó; as discrepâncias mais fortes entre os dois perfis se limitam a "cuidar" e "alimentar". O perfil de irmãos distingue-se dos outros quatro no número e na natureza das funções características. Esse quadro sugere que geração seja um diferencial mais importante do que gênero na definição dos perfis. Ser pai e mãe é diferente de ser avô e avó, e todos são diferentes de ser irmão. 
Tabela 3. Porcentagens de respostas válidas por membro da família.

\begin{tabular}{|c|c|c|c|c|c|}
\hline Categorias & Pai & Mãe & Avô & Avó & Irmãos \\
\hline a. Cuidar & $13^{*}$ & $18^{*}$ & $8 \mathrm{~ns}$ & $17 *$ & $9 \mathrm{~ns}$ \\
\hline b. Cuidar da casa & $0^{* *}$ & $12 *$ & $0 * *$ & $2 \mathrm{~ns}$ & $0 * *$ \\
\hline c. Alimentar & $0,6^{* *}$ & $2 \mathrm{~ns}$ & $2 \mathrm{~ns}$ & $15^{*}$ & $0 * *$ \\
\hline d. Sustentar/ trabalhar & $14^{*}$ & $8 \mathrm{~ns}$ & $4 \mathrm{~ns}$ & $0 * *$ & $0 * *$ \\
\hline $\begin{array}{l}\text { e. Educar/ ensinar/ orientar/ dar exemplo॰/ } \\
\text { aconselhar }(\cdot \text { irmãos) }\end{array}$ & $17^{*}$ & $12 *$ & $7 \mathrm{~ns}$ & $7 \mathrm{~ns}$ & $7 \mathrm{~ns}$ \\
\hline f. Disciplinar/mandar & $5 \mathrm{~ns}$ & $7 \mathrm{~ns}$ & $1^{* *}$ & $3 \mathrm{~ns}$ & $1^{* *}$ \\
\hline g. Permitir & $0 * *$ & $0,5 * *$ & $4 \mathrm{~ns}$ & $1 * *$ & $0 * *$ \\
\hline h. Ajudar & $9 \mathrm{~ns}$ & $7 \mathrm{~ns}$ & $10^{*}$ & $1 * *$ & $14^{*}$ \\
\hline i Proteger/ apoiar/ defender• (•irmãos) & $3 \mathrm{~ns}$ & $3 \mathrm{~ns}$ & $3 \mathrm{~ns}$ & $3 \mathrm{~ns}$ & $5 \mathrm{~ns}$ \\
\hline j. Dar amor/ amizade/ carinho/ respeito & $14^{*}$ & $16^{*}$ & $16^{*}$ & $15^{*}$ & $8 \mathrm{~ns}$ \\
\hline k. Dar coisas & $5 \mathrm{~ns}$ & $3 \mathrm{~ns}$ & $15^{*}$ & $13^{*}$ & $0 * *$ \\
\hline 1. brincar & $19^{*}$ & $10 *$ & $29 *$ & $19 *$ & $37 *$ \\
\hline m. Substituir (só avós) & $0 * *$ & $0^{* *}$ & $1^{* *}$ & $4 \mathrm{~ns}$ & $0 * *$ \\
\hline n. Fazer companhia (só irmãos) & $0^{* *}$ & $0 * *$ & $0 * *$ & $0 * *$ & $11^{*}$ \\
\hline o. Brigar/ pirraçar (só irmãos) & $0^{* *}$ & $0 * *$ & $0 * *$ & $0 * *$ & $17^{*}$ \\
\hline p. compartilhar segredos (só irmãos) & $0 * *$ & $0 * *$ & $0 * *$ & $0 * *$ & $3 \mathrm{~ns}$ \\
\hline
\end{tabular}

\section{Perfis dos membros da família}

(i)

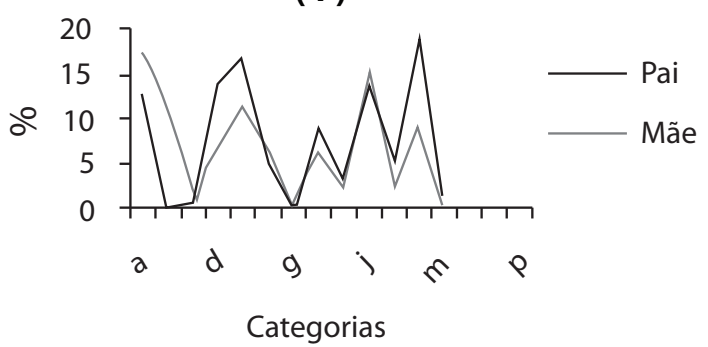

(ii )

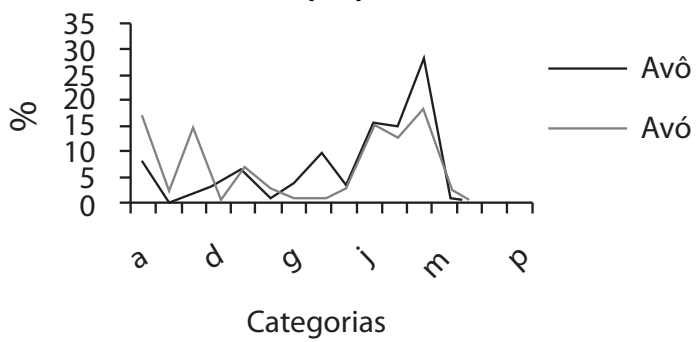

( iii )

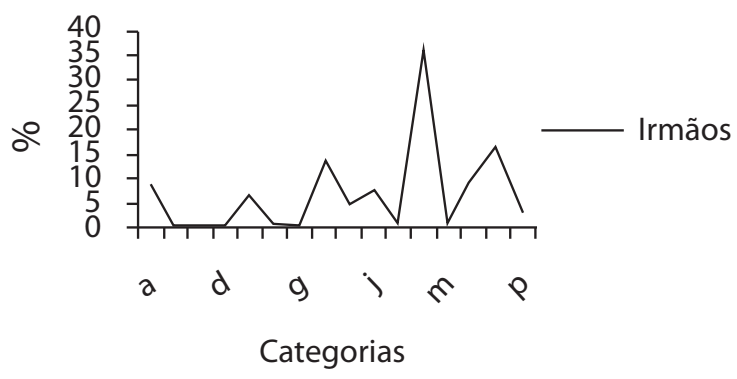

Figura 1. Porcentagem de respostas válidas pó membro da família. 
Tomando-se os picos de cada perfil (acima de 10\%, em ordem decrescente) temos:

(a) Ser pai é brincar, educar, sustentar e dar amor, e cuidar (genericamente);

(b) Ser mãe é cuidar (genericamente), dar amor, educar, cuidar da casa e brincar;

(c) Ser irmão é principalmente brincar, mas também pirraçar, ajudar e fazer companhia;

(d) Avôs caracterizam-se por brincar, dar amor, dar coisas e ajudar;

(e) Avós caracterizam-se por brincar, cuidar (genericamente), dar amor e alimentar (coisas gostosas) e dar coisas. É tentador sugerir que o alimentar da avó seja mais uma expressão de amor do que de cuidado físico: é mais afetivo do que orientado para nutrição/saúde. Pode-se pensar que o conjunto desses perfis, principalmente de seus aspectos mais salientes (significativamente altos), sintetiza o que a criança percebe como essencial na família. Essa ideia será retomada a seguir.

\section{Como a criança compreende a família?}

Foram categorizadas aqui respostas a perguntas sobre a família como um todo (o que é; como é; para que serve). Ao primeiro exame, essas categorias parecem espelhar os conteúdos produzidos em relação aos membros individualmente, sugerindo, portanto, que o conceito de família expresso pelas crianças seja, basicamente, a soma dos perfis de seus membros. No entanto, essa primeira impressão deve ser mais examinada.

Em primeiro lugar, é preciso apontar que questões sobre a família mostraram-se mais difíceis do que as relativas a cada membro, produzindo conteúdos mais vagos e menos diversificados, embora os termos que os resumem sejam semelhantes aos obtidos para os membros individualmente. Um possível indicador dessa dificuldade é a proporção baixa de respostas válidas. Entre as 120 entrevistas, quase a metade (59) foi classificada em três tipos de respostas consideradas não válidas: em $24 \%$ das entrevistas descartadas, respostas relativas à composição da família (família é pai, mãe, irmãos...), diante da pergunta "o que é família" e repetidas em "quem faz parte de sua família"; em 58\%, respostas valorativas (família é boa, legal, divertida, é a minha vida, é importante...), formuladas diante da primeira pergunta ("o que é"), e repetidas diante de "como é"; e em 19\%, não respondeu (não sei, é difícil, não sei explicar), o que foi mais frequente diante de "o que é família". Confirmando essa interpretação de respostas não válidas como indícios de dificuldade, elas foram significativamente mais frequentes no NSE baixo e pouco frequentes no NSE médio alto.

A dificuldade ao responder questões sobre a família sugere que a criança está tentando definir alguma coisa mais impalpável do que os membros individuais que a compõem - estes são concretos, observáveis, enquanto a família é uma abstração, tal como a noção de união que caracteriza a categoria "e". A família é mais do que os perfis de seus membros, mas não é fácil expressar em palavras em que consiste esse "mais".
Não é de surpreender que a criança considere difícil definir o que é família, já que esse conceito é controvertido mesmo entre estudiosos do tema. A família já foi definida por consanguinidade, por laços jurídicos, por coabitação etc. Um exemplo interessante no contexto deste estudo é a conceituação de Donati (2008). Segundo esse autor, a família se define por dois tipos de relações: uma horizontal, que envolve atividade sexual (o casal) e uma vertical, entre pais e filhos; irmãos não seriam incluídos como relação familiar, porque sua relação, essencialmente horizontal, não envolve sexualidade. A essência dessa definição parece ser a distinção geracional e a discriminação de suas especificidades, como presença (na relação horizontal) ou ausência (na relação vertical) de sexualidade.

Evidentemente, não é essa a concepção que nossos entrevistados, ainda que com dificuldade de expressá-la, têm sobre a família e sobre seus membros. Tanto a partir da análise feita no item 1, a respeito de coabitação como critério de família, quanto no item 2 , sobre a caracterização dos membros e de suas atribuições, a família conceituada pelas crianças aparece como um sistema de relações caracterizadas por status e papéis (ou funções) diferentes - possivelmente definidos por diferenças geracionais, mais do que por diferenças de gênero - e unificados principalmente por afetos. Essas relações claramente incluem aquelas que ocorrem entre irmãos, com reconhecimento de suas especificidades. E, ainda, além das funções somadas de todos os seus membros (dar amor/amizade, ajuda, cuidado, companhia, educação, diversão) e excluídas as mais concretas (cuidar da casa, dar coisas, trazer dinheiro para casa), parece haver um resíduo de significado que ultrapassa essa soma: união, confiança, definir o lugar da criança no mundo, ter alguém, contar com alguém, não ser sozinho na vida - que se aplica a todos os membros, e a nenhum isoladamente: aplica-se à "entidade família". Embora não o expresse claramente, a criança parece ter a intuição de que é na família que se dá a primeira definição de seu lugar e de sua individualidade - em outras palavras, de seu pertencimento e, portanto, de sua identidade.

A Tabela 4 e a Figura 2 apresentam esse perfil de família descrito pela incidência das categorias. É interessante notar que, diferentemente do que ocorre para os membros individuais, diversão/brincar está entre as duas últimas posições - a "entidade" família é coisa "séria"...

Uma questão paralela, que não emerge nesses resultados, pelo próprio fato de que a amostra é de crianças e, portanto, de famílias com filhos, é o conceito de família quando não há ou ainda não há filhos. Donati (2008) parece sugerir que um casal sem filhos não é uma família. Mas pode-se pensar que todos os atributos funcionais e afetivos utilizados pelas crianças também se aplicam a um casal: amor, união, ajuda, cuidado, convivência e companhia, confiança, diversão, briga - e até mesmo educação, se entendida em sentido amplo. Uma entrevistada apreendeu essas relatividades ao tentar definir família por sua composição: "Família é pai, mãe, irmãos... Mas também pode não ter irmão... É dificil...". Tanto nas concepções de família como nas de seus membros, permanece a intuição de que há algo a mais nas relações familiares, algo que não é apreendido pela descrição de funções ou de composição do grupo familiar. 
Tabela 4. Família - Número de respostas em cada categoria.

\begin{tabular}{lc}
\hline Categorias & $\mathbf{N}^{0}$ de respostas \\
\hline a. Amor/ carinho/ amizade/ respeito & $27^{*}$ \\
b. Cuidar/ fazer-dar tudo que precisa & 18 \\
c. Convivência/ companhia/ ter pessoas-um lar/ não viver só & 16 \\
d. Ajudar em tudo & 16 \\
e. União/ pessoas unidas & 8 \\
f. Confiança/ contar com & 8 \\
g. Educação/ ensino & 8 \\
h. Brincar/ divertir-se junto & 5 \\
i. Brigas & $3 * *$ \\
\hline
\end{tabular}

Nota: * significativamente alta; $* *$ significativamente baixa.

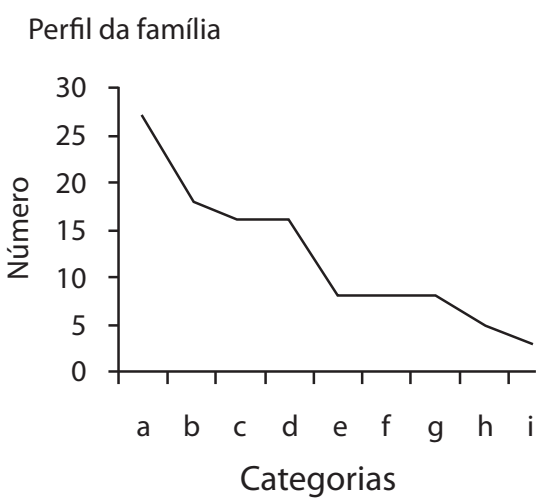

Figura 2. Número de respostas em cada categoria.

Dois dos entrevistados parecem se aproximar dessa intuição em respostas radicais: "Sem família, morre"; "Família é a vida". Família aparece como uma necessidade básica intuída, ainda que não definida.

Em síntese, parece que as crianças têm razão: família é uma daquelas coisas que todo mundo sabe o que é, mas pouca gente sabe definir.

\section{Há indícios de fatores exossistêmicos na construção dessas compreensões da criança?}

Como apontado na introdução, a ocorrência de diferenças em função das variáveis do estudo (região, contexto urbano e nível socioeducacional) poderia ser um indício de fatores exossistêmicos e/ou macrossistêmicos na construção da compreensão da criança sobre família, seus membros e funções que os caracterizam. A análise foi feita mediante a aplicação da análise do item 2, separadamente para cada variável. Pai e avó apresentam mais diferenças significativas em seus perfis (oito ou metade das categorias), seguidos por mãe (4), irmãos (2) e avôs (1). Sintetizando por perfis, temos:

Pai: Mais cuidador, provedor e amoroso no Sudeste e no interior; mais educador no interior e no NSE baixo; mais lúdico no Nordeste e no NSE médio alto. Menos disciplinador no Sudeste; menos protetor no Sudeste, na capital e no NSE baixo; menos presenteador no NSE médio alto;

Mãe: Mais amorosa no interior. Menos alimentadora no Sudeste; menos protetora no Nordeste, na capital e no NSE baixo; menos presenteadora no NSE baixo;

Avô: Mais amoroso no Nordeste e no NSE baixo;

Avó: Mais cuidadora no Sudeste e na capital; mais amorosa no Nordeste; mais alimentadora no Nordeste e no NSE médio alto; mais presenteadora na capital; mais lúdica no NSE médio alto; menos disciplinadora no Sudeste e no NSE médio alto; menos protetora no Nordeste; ajuda menos no interior;

Irmãos: Ajudam mais no interior e no NSE médio alto e fazem mais companhia no Nordeste e no NSE médio alto.

Não é fácil extrair desse quadro algum sentido consistente em termos de fatores exo- ou mesossistêmicos - por exemplo, ambiente cultural mais ou menos conservador, modo de vida mais cosmopolita ou mais provinciano, maior ou menor acesso à educação - dada a complexidade dos fatores em causa e o desconhecimento de seus mecanismos de operação em cada condição particular, além de seus efeitos interativos. Uma interpretação consistente só seria possível se as categorias fossem claramente decodificáveis em termos 
de valores culturais ligados a diferenças regionais, de modo de vida e de nível educacional, e se diferenças de ocorrência se mostrassem mais nítidas entre os valores das três variáveis. Da forma como se apresentam, estes dados sugerem antes uma reflexão sobre os procedimentos de coleta e de categorização, que é apresentada nas considerações finais.

\section{Considerações Finais}

Este tópico lida com algumas reflexões metodológicas inspiradas pelo estudo, agrupadas em três aspectos: coleta de dados; questões conceituais e categorização; e diferenças/ complementaridades entre enfoque qualitativo e quantitativo.

$\mathrm{O}$ delineamento deste estudo foi ambicioso em termos de coleta de dados, incluindo amostras representativas de três variáveis potencialmente relevantes: região, contexto urbano e NSE. O roteiro de entrevista foi construído sob a forma de entrevista semi-estruturada, com perguntas abertas e possibilidade de aprofundamento de significados com novas perguntas na medida do possível. As entrevistas foram gravadas e transcritas na íntegra, visando a preservação dos conteúdos com a maior fidelidade possível.

Um desafio colocado por esse delineamento é obter valores de variáveis passíveis de comparação. A escolha das regiões Sudeste e Nordeste e das cidades representantes dos dois contextos urbanos foi determinada por viabilidade de acesso dos pesquisadores a essas situações de coleta. A região Sudeste foi representada por São Paulo e o Nordeste pela Bahia, que são os principais estados de cada uma das regiões em termos de importância cultural, geográfica e econômica. O mesmo pode ser dito sobre suas capitais: São Paulo é a maior metrópole brasileira em termos de população e de importância econômica e cultural; Salvador é a maior capital do Nordeste e a terceira do país. Ambas têm características culturais marcantes: em São Paulo, uma cultura cosmopolita, influenciada pela imigração européia de diferentes origens; em Salvador, uma cultura marcada pela influência africana. Não é possível equiparar essas capitais em dimensões e características populacionais e de modo de vida resultante, mas ambas enfrentam os problemas característicos de grandes cidades brasileiras: altos índices de pobreza e desigualdade social, habitação, emprego, violência - e até mesmo trânsito, crescentemente problemático em Salvador, e quase insolúvel em São Paulo. Pode-se considerar, portanto, que essas escolhas são pertinentes.

$\mathrm{O}$ mesmo não se pode afirmar sobre o contexto urbano das cidades do interior. Franca, interior de São Paulo, tem 327.176 habitantes e é importante centro comercial e industrial da mais rica região do estado. Na Bahia, a coleta foi feita na maior parte em Cachoeira e complementada em Cruz das Almas (NSE médio alto) e Anguera (NSE baixo). As duas primeiras são próximas de Salvador, 30.500 e 58.000 habitantes, respectivamente, e têm economia centrada em produção rural; Anguera, também rural, tem apenas 9.500 habitantes. $\mathrm{O}$ que se supôs em comum entre essas cidades interioranas, por serem menores e distantes das capitais, é que representem mentalidades e modos de vida diferentes destas.

A terceira variável (nível socioeducacional) foi trabalhada em termos de localização de residências (bairros de classe média e de classe baixa) e de escolaridade dos pais. Consideramos, portanto, que a questão da representatividade das amostras em termos de região, contexto urbano e NSE foi razoavelmente resolvida, restando algumas dúvidas para o caso de contexto urbano quanto ao interior, esperando-se menor potencial de discriminação dessa variável - que não ocorreu no item 1 , mas se confirmou no item 2.

Uma segunda questão refere-se ao instrumento e ao procedimento de coleta. Os resultados obtidos indicam, em primeiro lugar, que as questões formuladas nem sempre estiveram ao alcance dos entrevistados, principalmente dada a dificuldade do tema. Poder-se-ia supor que a entrevista fosse um instrumento inadequado para a faixa etária analisada. Outras experiências de entrevista com crianças, no entanto, descartam essa suposição. Assim, por exemplo, Beraldo e Carvalho (2003) entrevistaram crianças de 5 a 10 anos, de NSE alto e baixo, sobre brincadeiras e hábitos lúdicos; com esse tema, as entrevistas fluíram com facilidade e de forma prazerosa para as crianças e com produção abundante de informações.

Deve ser considerado também o fato das entrevistas terem sido feitas por diversos entrevistadores. Apesar de supervisões regulares, o material mostra diferenças marcantes no aprofundamento das entrevistas: alguns entrevistadores detiveram-se na primeira resposta da criança, sem aprofundar seu sentido, usando o roteiro como questionário e não como guia de entrevista não estruturada. Essa heterogeneidade criou algumas dificuldades para a categorização.

Assim, parece que o roteiro não facilitou o trabalho dos entrevistadores e/ou que o treinamento e supervisão foram insuficientes diante da natureza do roteiro e/ou do tema. Para um trabalho exploratório, com questões abertas, talvez fosse preferível uma entrevista ainda menos estruturada, guiada apenas por tópicos, mais apropriada para uma análise qualitativa que não requereria uma amostragem tão ampla (mas requereria entrevistadores ainda mais treinados e experientes). Essa análise subsidiaria a formulação de categorias para um questionário mais fechado, adequado a uma análise quantitativa com amostra maior, como a realizada por Goetz e Vieira (2008).

Quanto à reflexão sobre conceitos e categorização, a categoria mais problemática parece ser "cuidar". Esse termo tem uma variedade de sentidos na língua: pensar, imaginar, refletir, atentar, tratar, preparar, zelar, encarregar-se de, ocupar-se/preocupar-se, desvelar-se e responsabilizar-se por, tomar conta de (Ferreira, 1999). Qual ou quais desses sentidos aplica-se ao cuidado familiar, ou qual o conceito subjacente? Essa categoria só foi utilizada nos casos em que não havia na resposta nenhuma pista sobre o tipo de cuidado. Não se pode garantir, portanto, que se trate de uma categoria homogênea: é possível que em muitas respostas as crianças tivessem em mente um tipo específico de cuidado (fazer comida, ou mesmo sustentar), que não foi especificado, e que entraria, caso o fosse, em outras categorias ("alimentar", "cuidar da casa", "sustentar"). Dessa forma, a participação da categoria "cuidar" nos perfis dos membros pode estar obscurecida (por exemplo, ao que se refere a criança quando diz que o pai cuida?). Por outro lado, diversas categorias que foram diferenciadas também são, estritamente, formas de cuidado: prover, educar, proteger, ajudar, ou mesmo dar 
amor e brincar. No entanto, se elas não fossem discriminadas, resultariam perfis menos claros ou mais vagos do que os que foram obtidos.

Apesar dessas imprecisões, e considerando também o uso do termo nas respostas sobre família, pode-se pensar que "cuidar" tem aqui um sentido genérico, de "ser responsável por" ou "tomar conta de". Esse sentido parece se aproximar do que Braga e Amazonas (2006) atribuem ao cuidado (inclusive físico, corporal) como suprimento de necessidades psicológicas e expressão de amor.

Um outro caso, um pouco diferente, é o das categorias "educar" e "disciplinar". Pode-se considerar que a disciplina é um componente da educação em sentido lato. Preferiu-se manter a distinção em função da especificidade das respostas que indicavam formas de disciplinamento via imposição de autoridade: repreender (dar bronca), dar ordens, punir. Em contrapartida, as respostas incluídas em "educar" referiam-se a aspectos gerais, como ensinar o certo-errado (educação moral), ajudar nas tarefas de escola (educação acadêmica), e formas de ensino (orientação, exemplo, aconselhamento). Ainda assim, a categoria "educar" pode ter ficado ampla demais: dar exemplo e aconselhar só apareceram para irmãos, sugerindo um conceito diferenciado na visão das crianças. O mesmo ocorreu na categoria "proteger", onde foi incluído "defender". Não foi suficientemente explorado, nas entrevistas, o sentido preciso de proteger - se genérico, com conotação próxima a cuidar (proteger na vida, cuidar de), ou se aplicável a certas situações (confrontos com outras pessoas, situações de risco).

Mais duas categorias envolvem ambiguidades. "Amizade" (ser amigo) foi incluída em dar amor, carinho etc., mas sua distribuição sugere que amor e carinho se diferenciam de amizade e, possivelmente, também de respeito (que talvez conote menos intimidade). Note-se que essa categoria apresenta alta frequência de menções, apenas superada por "brincar" e próxima de "cuidar". Apesar dessa similaridade, são três casos bem diferenciados em termos de questões conceituais: cuidar ficou inespecífico demais e, provavelmente, resultou em uma categoria heterogênea, por isso mesmo com alta incidência; dar amor também ficou heterogênea, mas por motivos diferentes: foi uma opção dos pesquisadores agrupar respostas que pareciam ter sentidos semelhantes, ao passo que em cuidar não foi possível subcategorizar por falta de especificação do conteúdo. Já em brincar não ocorrem dúvidas conceituais e a distribuição obtida é bastante informativa.

Ainda outro caso é “ajudar”. Quando aplicada aos membros da família, essa categoria parece envolver modalidades específicas de ajuda, como fazer algo junto com a criança, ou por ela, e aparece mais com irmãos do que com os membros adultos da família. É possível que a ajuda dos pais esteja descrita por outras palavras (por exemplo, cuidar) e que se refira a ajudar de forma genérica. É esse mesmo sentido que parece se aplicar quando a palavra ajuda se refere à família - um "ajudar em tudo", "na vida".

O processo de categorização sempre envolve um grau de arbitrariedade. Em outra análise baseada no mesmo conjunto de dados, foram utilizadas cinco categorias (significado afetivo, pessoas que ajudam, companhia/ relações, sentido da vida, fornece sustento) para a definição de família, que na presente análise foi recortada em
10 categorias. A questão relevante não é qual sistema de categorias é mais correto: é, antes, sua adequação para os objetivos da análise e sua consistência interna. Pode-se, por exemplo, indagar se "relações" não têm "significado afetivo", ou qual a diferença entre as respostas incluídas em cada uma dessas categorias. O esforço de definição das categorias é que conduz à sua clareza e consistência. O que apontamos aqui é que esse esforço é sempre incompleto, e deve ser visto criticamente para que se avalie a consistência dos resultados. E, principalmente, deve-se lembrar que categorias não podem ser reificadas: são nomes relativamente arbitrários para descrever recortes também arbitrários dos fenômenos registrados; o que as valida é sua utilidade para a compreensão desses fenômenos e seu potencial para progressos conceituais.

Finalmente, cabe abordar a questão das diferenças e complementaridades entre análise qualitativa e quantitativa. Em uma análise qualitativa baseada em respostas de crianças paulistas a esse mesmo roteiro de entrevista, o procedimento foi caracterizado nos seguintes termos (Rabinovich \& Moreira, 2008):

As respostas aos questionários foram organizadas holisticamente segundo os seus conteúdos (...) por se pretender entender o que estava subentendido a partir das respostas fornecidas. A análise ocorreu por uma leitura horizontal, em profundidade, (...) tentando captar os significados que o fenômeno em particular tinha para cada uma das crianças (...) e entender, assim, as diferenças entre elas. (p. 439)

Essa caracterização permite ressaltar algumas diferenças de procedimento entre análise qualitativa e quantitativa: uma organização holística, a partir de uma leitura horizontal, em profundidade, procurando compreender experiências e captar significados individuais. Em contraste, na análise quantitativa, o material é organizado por meio de sua decomposição em elementos, representados pelos valores das variáveis, por conceitos potencialmente úteis para a compreensão de diferenças e por significados sintetizados em um sistema de categorias; por meio deste, respostas individuais podem ser tratadas em grupo, para abordar questões quantitativas - isto é mais (ou menos) do que aquilo? - que só podem ser resolvidas pelo recurso a procedimentos estatísticos.

Tanto quanto a análise qualitativa, a análise quantitativa envolve opções com maior ou menor grau de arbitrariedade. É a explicitação dos critérios utilizados em cada uma dessas modalidades de análise que as valida, por permitir seu compartilhamento pela comunidade e, particularmente, pela comunidade científica (Carvalho, Pedrosa \& Amorim, 2006). Análise qualitativa e análise quantitativa não são, portanto, categorias opostas ou inconciliáveis: são diferentes, podem ser alternativas e frequentemente são complementares. Considera-se que seja este o presente caso, em que o mesmo material empírico foi examinado com os dois olhares. Uma forma de complementaridade, já sugerida anteriormente, é a análise qualitativa como etapa anterior a um enfoque quantitativo, possibilitando a elaboração prévia do sistema de categorias que será aplicado quantitativamente. Outra forma seria complementar a presente análise quantitativa com um novo enfoque qualitativo, seguindo pistas dadas 
pelas dificuldades de categorização e visando aprofundar e esclarecer os conceitos subjacentes a essa categorização ou a outras possíveis.

Além dessa direção de pesquisa futura e de algumas sugestões feitas ao longo do texto, este trabalho enseja mais duas, uma das quais, sobre gênero e geração como fatores de diferenciação dos perfis, está sendo empreendida em outra publicação (Carvalho, Rabinovich \& Moreira, 2010). Uma segunda é inspirada pela constatação da dificuldade do tema "família" em termos de conceituação: seriam os adultos mais capazes dessa conceituação do que se mostraram as crianças que entrevistamos? A comparação entre respostas de adultos e de crianças a questões do tipo das que foram utilizadas nas entrevistas realizadas no presente estudo poderia contribuir para o refinamento de terminologia relevante para a caracterização do fenômeno "família" e para o aprofundamento de conceitos úteis para a teorização a respeito do tema.

\section{Referências}

Beraldo, K. E. A., \& Carvalho, A. M. A. (2003). Na cidade grande. Em A. M. A. Carvalho, C. M. C. Guimarães, F. A. R. Pontes \& I. D. Bichara (Orgs.), Brincadeira e cultura-viajando pelo Brasil que brinca, Vol. 1 (pp. 157-185). São Paulo: Casa do Psicólogo.

Braga, M. G. R., \& Amazonas, M. C. L. A. (2006) Reprodução assistida e subjetivação infantil. Psyché, 10, 129-148.

Bronfenbrenner, U. (1996). A ecologia do desenvolvimento humano: experimentos naturais e planejados. Porto Alegre: ArtMed. (Trabalho original publicado em 1979)

Carvalho, A. M. A., Beraldo, K. E. A., Pedrosa, M. I., \& Coelho, M. T. (2004). O uso de entrevistas em estudos com crianças. Psicologia em Estudo, 9, 291-300.

Carvalho, A. M. A., Pedrosa, M. I., \& Amorim, K. S. (2006). Retomando o debate qualidade $\mathrm{x}$ quantidade: uma reflexão a partir de experiências de pesquisa. Temas em Psicologia, 14, 51-62.

Carvalho, A. M. A., Rabinovich, E. P., \& Moreira, L. V. C. (2010). Compreensão da criança sobre os membros da família: relações com gênero e posição na rede familiar. Em L. V. C. Moreira, G. C. Petrini \& F. B. Barbosa (Orgs.), O pai na sociedade contemporânea (pp. 181-200). Bauru: EDUSC.
Ciba-Geigy Co. (1971). Tablas cientificas (6 $6^{\mathrm{a}}$ ed.). Basilea: Ciba-Geigy Co.

Donati, P. (2008). Família no século XXI: abordagem relacional. São Paulo: Paulinas.

Dessen, M. A., \& Braz, M. P. (2000). Rede social de apoio durante transições familiares decorrentes do nascimento de filhos. Psicologia: Teoria e Pesquisa, 16, 221-231.

Goetz, E. R., \& Vieira, M. L. (2008). Diferenças nas percepções de crianças sobre cuidado parental real e ideal quando pais vivem juntos ou separados. Psicologia: Reflexão e Crítica, 21, 83-90.

Gomes, A. J. S., \& Resende, V. R. (2004). O pai presente: o desvelar da paternidade em uma família contemporânea. Psicologia: Teoria e Pesquisa, 20, 119-125.

Ferreira, A. B. H. (1999). Dicionário Aurélio Eletrônico: Século XXI, Versão 3.0. Rio de Janeiro: Nova Fronteira/Lexikon Informática.

Hinde, R. A. (1982). Ethology - its nature and relations with other sciences. Londres: Fontana Paperbacks.

Moreira, L. V. C. (2005). Concepções e práticas de pais sobre educação de filhos. Tese de Doutorado, Universidade de São Paulo, Ribeirão Preto.

Moreira, L. V. C., Rabinovich, E. P., \& Silva, C. N. (2009). Olhares de crianças baianas sobre família. Paidéia, 19, 77-85.

Rabinovich, E. P., \& Moreira, L. V. C. (2008). Significados de família para crianças paulistas. Psicologia em Estudo, 13, 437-445.

Souza, R. M. (2000). Depois que papai e mamãe se separaram: um relato dos filhos. Psicologia: Teoria e Pesquisa, 16, 203-211. 